\title{
RETOS DE LA AYUDA HUMANITARIA EN CONFLICTOS ARMADOS PROLONGADOS: EL ROL CRECIENTE DE LOS AGENTES LOCALES *
}

\author{
Elisenda Calvet Martínez
}

\begin{abstract}
SUMARIO: 1. INTRODUCCIÓN.-2. LA OBSTACULIZACIÓN DE LA AYUDA HUMANITARIA EN LOS CONFLICTOS ARMADOS PROLONGADOS.-2.1. La denegación arbitraria del acceso a la ayuda humanitaria.-2.2. Hambruna como arma de guerra.-2.3. Aumento de la violencia contra las operaciones de ayuda humanitaria.-3. EL ROL CRECIENTE DE LOS AGENTES LOCALES EN LOS CONFLICTOS ARMADOS PROLONGADOS.-3.1. La necesidad de incorporar a los agentes locales en la ayuda humanitaria y su relación con las agencias humanitarias internacionales.-3.2. La financiación insuficiente de los agentes locales.-3.3. El fomento de la capacidad local mediante estrategias a largo plazo.- 4. LA CUMBRE HUMANITARIA MUNDIAL: COMPROMISOS ADQUIRIDOS PARA EL EMPODERAMIENTO DE LOS AGENTES LOCALES.-5. CONCLUSIONES.
\end{abstract}

\section{INTRODUCCIÓN}

Los conflictos armados actuales no solo tienden a prolongarse en el tiempo sino que además se caracterizan por ser de naturaleza asimétrica, la proliferación de actores no estatales, la tendencia a atacar a la población civil, el aumento de la violencia contra las operaciones humanitarias, el despliegue de misiones de mantenimiento de la paz «robustas» de las Naciones Unidas, etc. De modo que el "espacio humanitario» ${ }^{1}$ se ha ido restringiendo considerablemente hasta llegar a la situación en la que el acceso de la ayuda humanitaria en conflictos como el de Yemen o Siria ha sido constantemente denegado, provocando hambruna entre la población civil.

* El presente trabajo se basa en una comunicación presentada en el seminario organizado por la AEPDIRI y el IBEI sobre «Humanitarismo y Relaciones Internacionales. Entre desafíos institucionales y controversia normativa» en Barcelona el 28 de abril de 2016. Además se enmarca en el proyecto de investigación DER2015-67026-P sobre La territorialidad como límite de la jurisdicción del Estado ante conductas de actores privados no estatales que repercuten en la efectividad de los derechos humanos internacionales, del Ministerio de Economía y Competitividad concedido a la Universidad de Barcelona. Elisenda Calvet Martínez es Investigadora postdoctoral de Derecho internacional público de la Universidad de Barcelona. Email: elisendacalvet@ub.edu.

1 Hubert, D. y Brassard-Boudreau, C., «Shrinking Humanitarian Space? Trends and Prospects on Security and Access», The Journal of Humanitarian Assistance, 2010. 
La ayuda humanitaria incluye no solo la ayuda de emergencia sino también actividades más a largo plazo dirigida a refugiados y desplazados internos, y tiene por objeto no solo la supervivencia inmediata sino que también lleva a cabo actividades que contribuyan al desarrollo y a la prevención de conflictos y preparación para futuros desastres naturales ${ }^{2}$, mientras que la asistencia humanitaria consiste en el «envío de bienes o prestación de servicios a las víctimas de un conflicto armado que son incapaces, con sus propios medios, de satisfacer sus necesidades básicas ${ }^{3}$.

Por otra parte, la acción humanitaria tiene un sentido más amplio y comprende un «conjunto diverso de acciones de ayuda a las víctimas de desastres (desencadenados por catástrofes naturales o por conflictos armados), orientadas a aliviar su sufrimiento, garantizar su subsistencia, proteger sus derechos fundamentales y defender su dignidad, así como, a veces, a frenar el proceso de desestructuración socioeconómica de la comunidad y prepararlos ante desastres naturales. Puede ser proporcionado por actores nacionales o internacionales» ${ }^{4}$.

Si bien la imposibilidad de los organismos internacionales de proporcionar la ayuda humanitaria adecuada en contextos de crisis humanitarias no es una novedad, la complejidad de los conflictos armados prolongados actuales ha vuelto a plantear la necesidad de contar con una participación más significativa de Organizaciones no Gubernamentales (ONG) de carácter nacional y local para garantizar el acceso de la ayuda y suministros de socorro a la población civil. Hasta el momento, las agencias humanitarias internacionales se han limitado, por lo general, a subcontratar a personal local, a menudo estableciendo una relación desigual de poder, y subestimando las capacidades, conocimientos y cultura de los agentes locales ${ }^{5}$. Sin embargo, el liderazgo local tampoco es una panacea y no siempre es posible o adecuado, bien porque el Estado no quiere responsabilizarse de la ayuda humanitaria o bien porque es parte del conflicto y no tiene la capacidad de proteger a su propia población ${ }^{6}$. En este sentido, también puede ocurrir que el apoyo al personal local

2 La ayuda de emergencia es la proporcionada con un carácter de urgencia a las víctimas de desastres naturales o conflictos armados y que consiste en el suministro de bienes y servicios esenciales para la supervivencia de la población civil, en un plazo entre seis y doce meses. Para más detalle sobre los conceptos de ayuda humanitaria y distinción con otras figuras similares, véase ABRISKETA, J. y PÉREZ DE ARMiÑo, C., «Acción humanitaria: concepto y evolución», Diccionario de Acción Humanitaria y Cooperación al Desarrollo, Bilbao, HEGOA, 2005-2006, disponible en el siguiente enlace: http://www.dicc. hegoa.ehu.es/listar/mostrar/1 (consultada el 20 de octubre de 2016).

3 Abril Stoffels, R., La asistencia humanitaria en los conflictos armados, Valencia, Tirant lo Blanch, 2001, p. 40.

4 Abrisketa, J. y Pérez de Armiño, C., op. cit., nota 2.

5 Africa Development Solution, "A more Dignified and Equitable Humanitarian System», julio de 2015, disponible en el siguiente enlace: http://adesoafrica.org/newsroom/newsroom/a-more-dignifiedand-equitable-humanitarian-system/?keywords=equitable+humanitarian+system (consultada el 20 de octubre de 2016).

${ }^{6}$ Gingerigh, T. R. y COHEN, M. J., Turning the humanitarian system on its head: saving lives and livelihoods by strengthening local capacity and shifting leadership to local actors, Oxfam Research Reports, julio de 2015, p. 5 . 
refuerce las estructuras de poder que forman parte del conflicto, exacerbando el conflicto armado ${ }^{7}$.

Por otra parte, el sistema humanitario tradicional hace tiempo que viene replanteándose ante la aparición de «nuevos» donantes, ONG del Sur, organizaciones regionales, asociaciones de la diáspora o actores privados que reclaman un mayor reconocimiento de su labor ${ }^{8}$. Así, el sistema humanitario está compuesto por unos actores principales cuya actividad esencial es la acción humanitaria, mientras que otras entidades pueden desarrollar un papel importante en la ayuda, pero tienen otros objetivos principales. De entre los actores principales se puede destacar: las ONG locales, nacionales e internacionales; las agencias humanitarias de la ONU, el Movimiento Internacional de la Cruz Roja (MICR) y de la Media Luna Roja (MLR); organismos de gobiernos afectados con responsabilidad de respuesta a la crisis; departamentos humanitarios de organizaciones intergubernamentales regionales y organismos de gobiernos donantes que proporcionan financiación y coordinación humanitaria. En cambio, otros actores como las fuerzas armadas, las organizaciones confesionales, las empresas o las organizaciones de la diáspora pueden desempeñar un papel importante en la respuesta humanitaria aunque su función principal no sea la acción humanitaria ${ }^{9}$.

En todo caso, la cuestión principal es cómo hacer que la ayuda humanitaria sea más efectiva y pueda integrar de forma más equitativa a los distintos actores que participan en el sistema humanitario. Es por este motivo por lo que en mayo de 2016, bajo los auspicios de las Naciones Unidas, se convocó la Primera Cumbre Humanitaria Mundial en la que representantes de los Estados miembros, las ONG, la sociedad civil, las poblaciones afectadas por las crisis, el sector privado y las organizaciones internacionales se reunieron para comprometerse a reducir de manera colectiva e individual las necesidades humanitarias y el sufrimiento sin precedentes en todo el mundo. La cuestión de la «localización» de la ayuda humanitaria fue una de las cuestiones centrales del debate y constituye uno de los cinco puntos de la Agenda

\footnotetext{
7 Anderson, M. B., "You Save My Life Today, But for What Tomorrow? Somme Moral Dilemmas of Humanitarian Aid», en Moore, J., Hard Choices: Moral Dilemmas in Humanitarian Intervention, Lanham, Rowman \& Littlefield, 1998, p. 145. La autora menciona el caso de los campos de refugiados ruandeses en el Zaire en 1994 en los que las agencias humanitarias decidieron distribuir la ayuda a través de los líderes locales, y luego resultó que formaban parte de la comunidad Hutu responsable del genocidio en Ruanda, que aprovecharon los recursos de la ayuda humanitaria para controlar a la población civil y para rearmarse y volver a la guerra.

8 Pantuliano, S., "The Changing Nature of Humanitarian Assistance», New World, UNA-UK, Spring, 2014, p. 8. Por asociaciones de la diáspora, si bien no hay una definición consensuada, comprende a grupos de migrantes o descendientes de migrantes que viven fuera de su país pero que aún mantienen contacto con sus lugares de origen. Las asociaciones de diáspora no forman grupos homogéneos en cuanto a capacidad o perspectiva política y no necesariamente operan conforme a los principios humanitarios, pero cada vez tienen un papel más relevante en el ámbito humanitario y de desarrollo en situaciones de crisis humanitarias. Véanse, entre otros, INTERNATIONAL ORGANIZATION FOR MigRation, The Role of Diaspora in Humanitarian Response Summary, Nueva York, julio de 2015.

9 Alnap, El estado del sistema humanitario, 2015, p. 18.
} 
Humanitaria propuesta por el Secretario General Ban Ki-moon con ocasión del encuentro ${ }^{10}$.

Esta contribución tiene por objeto analizar la naturaleza y características específicas de los conflictos armados prolongados y la restricción del acceso de la ayuda humanitaria en estos, identificando como posibles causas la obstaculización constante de la ayuda humanitaria por las diferentes partes en conflicto, el uso de la hambruna como arma de guerra (en violación del Derecho internacional humanitario) y el aumento de la violencia contra las operaciones humanitarias. A continuación, se analizará el rol creciente de los agentes locales en los conflictos armados prolongados y la necesidad de contar con una mayor participación de las ONG nacionales y locales, no solo por su proximidad, conocimiento del entorno y capacidad para llegar a la población que está fuera del alcance de los actores internacionales, sino también para mejorar la eficacia de la ayuda humanitaria. Para ello será necesario revisar la relación entre los agentes locales y las agencias internacionales, conseguir una mayor financiación directa de los agentes locales (en la actualidad no alcanza el 0,2 por 100) y fomentar la capacidad local mediante estrategias a largo plazo. Posteriormente, se examinarán los compromisos adquiridos en la Cumbre Humanitaria Mundial relativos a la «localización» de la ayuda humanitaria y se terminará con unas conclusiones.

\section{LA OBSTACULIZACIÓN DE LA AYUDA HUMANITARIA EN LOS CONFLICTOS ARMADOS PROLONGADOS}

El término «conflictos armados prolongados» no se encuentra regulado por el Derecho internacional humanitario, el cual solamente distingue entre conflictos armados de carácter internacional y de carácter no internacional, dejando fuera de su alcance las tensiones internas y disturbios interiores ${ }^{11}$. En este sentido, el Tribunal Penal Internacional para la ex Yugoslavia (TPIY), dada la complejidad de los conflictos armados actuales y con miras a superar esta distinción, ha establecido que existe un conflicto armado «whenever there is a resort to armed force between States or protracted armed violence between governmental authorities and organized armed groups or between such groups within a State» ${ }^{12}$. Si bien el TPIY establece que hay que analizar caso por

10 Una humanidad: nuestra responsabilidad compartida, Informe del Secretario General para la Cumbre Humanitaria Mundial, ONU Doc. A/70/709, de 2 de febrero de 2016.

11 Arts. 2 y 3 común a los cuatro Convenios de Ginebra de 12 de agosto de 1949; art. 54.1 del Protocolo Adicional a los Convenios de Ginebra de 12 de agosto de 1949 relativo a la protección de las víctimas de los conflictos armados internacionales (Protocolo Adicional I) y art. 1 del Protocolo Adicional a los Convenios de Ginebra de 12 de agosto de 1949 relativo a la protección de las víctimas de los conflictos armados sin carácter internacional (Protocolo Adicional II). Para una mayor discusión sobre el concepto y tipología de conflictos armados, véase VITÉ, S., «Typology of armed conflict in International humanitarian law: legal concepts and actual situations», International Review of the Red Cross, vol. 91, 2009, núm. 873, pp. 69-94.

12 Véanse, entre otros, TPIY, Prosecutorv. Tadic, caso núm. IT-94-1-AR72 (Sala de Apelaciones), decisión de 2 de octubre de 1995, párr. 70; y Prosecutor v. Kupreskic et al., caso núm. IT-95-16-T, Sentencia de 14 de enero de 2000, párr. 545. 
caso, utiliza como criterios la intensidad y la organización para determinar si existe un conflicto armado ${ }^{13}$.

No obstante, cada vez más, los conflictos armados, sin importar si son de carácter internacional o interno, tienden a prolongarse en el tiempo, convirtiéndose en «emergencias complejas crónicas» ${ }^{14}$ en las que el conflicto de larga duración se debe a las estructuras de gobierno débiles y pobreza severa, lo cual hace que las necesidades de la población civil no sean una cuestión puntual sino que perduran en el tiempo, siendo necesario plantear la acción humanitaria más a largo plazo. Así, de los 58 países que recibieron asistencia humanitaria en 2014, el 84 por 100 la habían recibido cada año durante los cinco años anteriores, y el 69 por 100 estaban recibiendo ayuda por décimo año consecutivo ${ }^{15}$.

Los conflictos armados prolongados pueden definirse como aquellos que comprenden interacciones hostiles que se extienden durante largos periodos de tiempo con brotes esporádicos de guerra abierta que fluctúan en frecuencia e intensidad y en los que no hay una perspectiva de terminación ${ }^{16}$. En la actualidad, se podrían considerar conflictos de esta naturaleza la situación de Siria, Yemen, Ucrania, República Centroafricana, Mali, Nigeria y los países de la región de los Grandes Lagos. Si bien la existencia de conflictos armados prolongados no es una novedad, los de hoy se caracterizan por nuevos factores que dificultan el ejercicio y acceso de la ayuda humanitaria.

En este sentido, el Comité Internacional de la Cruz Roja (CICR), en un reciente estudio sobre conflictos armados prolongados, destaca que estos tienden a darse en zonas urbanas y a desarrollarse tanto en países pobres

13 En relación a la intensidad, el TPIY tiene en cuenta los siguientes factores: "The factors taken into account to assess the intensity of the conflict include the seriousness of attacks and whether there has been an increase in armed clashes; the spread of clashes over territory and over a period of time; any increase in number of government forces and mobilization and the distribution of weapons among both parties to the conflict; involvement of the UN Security Council; number of civilians forced to flee from the combat zones; types of weapons used, particularly heavy weapons, and other military equipment, such as tanks and other heavy vehicles; the blockading or besieging of towns and heavy shelling of towns; the extent of destruction and number of casualties caused by shelling or fighting; [...] including the protracted nature, of violence which has required the engagement of the armed forces and the high number of casualties and extent of material destruction»: véase TPIY, Prosecutor v. Haradinaj, caso núm. IT-04-84bis-T, Sentencia de 29 de noviembre de 2012, párr. 394.

14 Alnap, op. cit., nota 10, p. 32. Fischer y Jaime Oráa definen «emergencias complejas» como las situaciones en las que una catástrofe natural o una emergencia de otro tipo se suma a un conflicto bélico como, por ejemplo, una situación de hambre en un país que sufre una guerra civil: véase FISCHER, H. y ORÁA, J., Derecho internacional y ayuda humanitaria, Bilbao, Universidad de Deusto, 2000, p. 60.

15 AlnAP, op. cit., nota 10, p. 32.

16 Azar, E., Jureidini, P. y Mclaurin, R., «Protracted social conflict; Theory and practice in the Middle East», Journal of Palestine Studies, vol. 8, 1978, núm. 1, pp. 41-60, p. 50. Para Edward Azar, los conflictos prolongados se distinguen por las siguientes características: "Duration (protractedness) of a high-conflict NRR (Normal Relations Range); fluctuation in the intensity and frequency of interaction; conflict spillover into all domains; strong equilibrating forces that constrain interactions to remain within the existing NRR and force interaction trends back to the NRR when they go beyond its boundaries whether in conflict or cooperation; the absence of a distinct termination". 
como de ingresos medios. Además, estos conflictos pueden constituir un solo conflicto a lo largo del tiempo o una serie de conflictos y se caracterizan por su fragmentación y mutación constante e intensidad variable. Asimismo, los conflictos armados internos prolongados suelen internacionalizarse en diferentes momentos y niveles, ya sea a través de la intervención de Estados o de organizaciones internacionales, y tienen un impacto cumulativo al degradar de forma progresiva las infraestructuras, los servicios, las condiciones de vida y la dignidad de la población civil provocando fragilidad en los sistemas económicos y sociales. Finalmente, el CICR resalta la concentración del sufrimiento en los conflictos armados prolongados, como es el caso de los desplazados y refugiados. En este sentido, 8,6 millones de nuevos desplazados internos en el 2015 tuvieron lugar en Iraq, Siria y Yemen, y en cifras globales, el 54 por 100 de los refugiados de todo el mundo provenían de tres países solamente en el 2015 (Siria, Afganistán y Somalia ${ }^{17}$. De modo que los conflictos prolongados se han convertido en «the new normal» con la consiguiente complejidad de necesidades y la diversidad de respuestas que requieren, y así lo ha reconocido la Cumbre Humanitaria Mundial ${ }^{18}$.

Como se verá a continuación, la denegación del acceso de la ayuda humanitaria, la utilización de la hambruna como arma de guerra y el aumento de la violencia contra las operaciones humanitarias en el contexto de conflictos armados prolongados son algunos de los retos a los que se debe enfrentar el sistema humanitario en la actualidad. Además, la denegación arbitraria del acceso humanitario y la privación de bienes indispensables para la supervivencia de la población civil, incluyendo la obstaculización deliberada del suministro de socorro y acceso a la asistencia humanitaria, constituyen una violación del Derecho internacional. Esta reducción del «espacio humanitario» se debe, en cierta medida, a que la ayuda humanitaria muchas veces se confunde con otro tipo de intervenciones internacionales de carácter militar, y es vista por los distintos grupos armados y la población civil con falta de imparcialidad, neutralidad e independencia.

\subsection{La denegación arbitraria del acceso de la ayuda humanitaria}

La responsabilidad primordial de cubrir las necesidades básicas de la población civil corresponde a las partes en conflicto y así está reconocido por la Asamblea General en los principios rectores para el fortalecimiento de la coordinación de la asistencia humanitaria de emergencia del sistema de las Naciones Unidas:

17 COMItÉ InTERnacional de LA CRUz Roja, Protracted conflict and humanitarian action. Some recent experiences, Ginebra, agosto de 2016, pp. 9-11.

18 Tsolakoglou, A., The first UN World Humanitarian Summit: Results, omissions, and future goals, disponible en http://www.solidaritynow.org/grafeio-tupou_en/publications_en.html?id=169\&lang=_en (consultada el 20 de octubre de 2016). 
«Cada Estado tiene la responsabilidad primordial y principal de ocuparse de las víctimas de desastres naturales y otras emergencias que se produzcan en su territorio. Por tanto, corresponde al Estado afectado el papel principal en la iniciación, organización, coordinación y prestación de asistencia humanitaria dentro de su territorio» ${ }^{19}$.

Por otro lado, conforme a la soberanía de los Estados y los principios de integridad territorial y de no intervención, la asistencia humanitaria «deberá proporcionarse con el consentimiento del país afectado y, en principio, sobre la base de una petición del país afectado ${ }^{20}$. En los conflictos armados internacionales, el Derecho internacional humanitario prevé que los Estados «autorizarán el libre paso de todo envío de medicamentos y de material sanitario [...] destinados únicamente a la población civil» ${ }^{21}$, "permitirán y facilitarán el paso rápido y sin trabas de todos los envíos, materiales y personal de socorro»y, en todo caso, «el ofrecimiento de tales socorros no será considerado como injerencia en el conflicto ni como acto hostil» 22 .

Para los conflictos armados internos, el art. 3 común a los cuatro Convenios de Ginebra de 1949 reconoce el derecho de iniciativa humanitaria al establecer que una organización imparcial «podrá ofrecer» sus servicios a las partes en conflicto, mientras que el Protocolo Adicional II dispone en su art. 18.2 que «cuando la población civil esté padeciendo privaciones extremadas por la falta de abastecimientos indispensables para su supervivencia»se llevarán a cabo acciones de asistencia humanitaria con el consentimiento de los Estados, siempre que sea realizada mediante los principios de neutralidad e imparcialidad.

De modo que, como regla general, se necesita el consentimiento de los Estados para poder llevar a cabo acciones de ayuda humanitaria en situaciones de conflicto armado, si bien este consentimiento no puede ser arbitrariamente denegado $^{23}$. Igualmente, la obligación de las partes en conflicto de permitir y facilitar el paso rápido y sin trabas de toda ayuda humanitaria destinada a las personas civiles necesitadas siempre que tenga carácter imparcial y se preste sin distinción desfavorable alguna, es una norma de carácter consuetudinario aplicable tanto a los conflictos armados internacionales como internos ${ }^{24}$.

19 Asamblea General, Resolución 46/182, de 19 de diciembre de 1991, principio 4. Véase también, Comisión de Derechos Humanos, Principios rectores de los desplazamientos internos, ONU Doc. E/CN.4/1998/53/Add.2, de 11 de febrero de 1998: «Las autoridades nacionales tienen la obligación y la responsabilidad primarias de proporcionar protección y asistencia humanitaria a los desplazados internos que se encuentren en el ámbito de su Jurisdicción» (Principio 3), y "La obligación y responsabilidad primarias de proporcionar asistencia humanitaria a los desplazados internos corresponde a las autoridades nacionales».

20 Asamblea General, Resolución 46/182, op. cit., nota 20, principio 3.

21 Art. 23 del IV Convenio de Ginebra de 12 de agosto de 1949 relativo a la protección debida a las personas civiles en tiempo de guerra.

22 Art. 70 del Protocolo Adicional I.

${ }^{23}$ OсHA, Oxford Guidance on the Law Relating to Humanitarian Relief Operations in Situations of Armed Conflict, octubre de 2016, p. 16.

${ }^{24}$ Henckaerts, J.-M. y Doswald-Beck, L., El derecho internacional humanitario consuetudinario, vol. I, Normas, Ginebra, CICR, 2007, norma 55. En este sentido, Ruth Abril distingue entre autori- 
La obstaculización de la ayuda humanitaria en conflictos armados no es una cuestión nueva sino que ya se dio en los años noventa en los Balcanes, y en especial en Bosnia y Herzegovina en donde la denegación de la asistencia humanitaria se convirtió en un instrumento de guerra, dando pie a la llamada «intervención humanitaria» ${ }^{25}$. A diferencia de la ayuda humanitaria, la intervención humanitaria reside en la «acción comprendida por uno o más Estados [...] en otro Estado consistente en el uso de la fuerza dirigida a salvaguardar y proteger los derechos humanos más fundamentales» ${ }^{26}$, mientras que la injerencia humanitaria implica la prestación de ayuda humanitaria a las víctimas de conflictos armados denegada de forma arbitraria por las autoridades competentes pero sin el empleo de la fuerza ${ }^{27}$.

Ante los fracasos de las intervenciones de la comunidad internacional en Somalia, Ruanda y Kosovo, la legitimidad de la intervención humanitaria fue cuestionada y objeto de debate. Así, en el 2001 surgió la doctrina de la «responsabilidad de proteger» en la que se establece que cada Estado es responsable de proteger a su población del genocidio, los crímenes de guerra, la depuración étnica y los crímenes de lesa humanidad ${ }^{28}$. Asimismo, la comunidad internacional, por medio de las Naciones Unidas, «tiene también la responsabilidad de utilizar los medios diplomáticos, humanitarios y otros medios pacíficos apropiados» para ayudar a proteger a la población civil ante graves violaciones de derechos humanos y en última instancia adoptar medidas colectivas de conformidad con el capítulo VII de la Carta de las Naciones Unidas si los medios pacíficos resultan inadecuados y las autoridades nacionales no protegen debidamente a la población civil ante estos crímenes ${ }^{29}$.

zación de la ayuda humanitaria que en principio corresponde a los Estados, del consentimiento, que deben darlo todas las Partes en conflicto que están en condiciones de obstaculizar o impedir la entrada de la asistencia humanitaria. Para más detalle, véase ABRIL STOFFELS, R., op. cit., nota 4, pp. 286-297.

25 Véase, entre otras, la Resolución 770 (1992), de 13 de agosto, en la que el Consejo de Seguridad insta a los Estados a que tomen «todas las medidas necesarias» para facilitar el suministro de asistencia humanitaria a Sarajevo y todas las demás partes de Bosnia y Herzegovina en que fuera necesario.

26 Escudero Espinosa, J. F., Cuestiones en torno a la intervención humanitaria y el derecho internacional actual, León, Servicio de Publicaciones de la Universidad de León, 2002, p. 310.

27 Véase, entre otros, Márouez Carrasco, C., «La práctica del Consejo de Seguridad en torno a la asistencia y la injerencia humanitaria», en RAMón CHORnET, C. (ed.), Problemas actuales del derecho internacional humanitario. V Jornadas de Derecho Internacional Humanitario, Valencia, Tirant lo Blanch, 2004, pp. 153-171; y AbRIL StofFels, R., op. cit., nota 4, p. 50.

28 Asamblea General, Documento Final de la Cumbre Mundial, Resolución 60/1, de 16 de septiembre de 2005, párrs. 138-140. Véase, también, La responsabilidad de proteger: informe de la Comisión Internacional sobre Intervención y Soberanía de los Estados, diciembre de 2001; SECRETARIO GENERAL, Un concepto más amplio de la libertad: desarrollo, seguridad y derechos humanos para todos, ONU Doc. A/59/2005, de 21 de marzo de 2005; y SECRETARIO GENERAL, Hacer efectiva la responsabilidad de proteger, ONU Doc. A/63/67, de 12 de enero de 2009.

29 Para más información sobre la noción y alcance de la «responsabilidad de proteger», véase, entre otros, García PÉrez, R., "La "responsabilidad de proteger": un nuevo papel para Naciones Unidas en la gestión de la seguridad internacional», REEI, 2006, núm. 11, pp. 1-18; Díaz BARRADo, C. M., «La responsabilidad de proteger en el derecho internacional contemporáneo: entre lo conceptual y la práctica internacional», REEI, 2012, núm. 24, pp. 7-40; 
Desde el estallido del conflicto en Siria en 2011, las Naciones Unidas han venido haciendo un llamamiento a las autoridades sirias para que «den al personal de asistencia humanitaria acceso inmediato, cabal e irrestricto a toda la población que necesite asistencia, de conformidad con el Derecho internacional y los principios rectores de la asistencia humanitaria» ${ }^{30}$. En este sentido, el propio Consejo de Seguridad manifestaba su preocupación por la difícil situación de los cerca de 393.700 civiles atrapados en zonas asediadas y de la situación de más de 4,5 millones de personas que viven en zonas de difícil acceso y denunciaba las dificultades para proporcionar acceso para la asistencia humanitaria a todos los civiles necesitados dentro de Siria ${ }^{31}$. Así, en el 2015, las Naciones Unidas tan solo pudieron hacer llegar el 3,5 por 100 de la asistencia en salud de la población asediada y el 0,7 por 100 de la asistencia alimentaria de la población por mes ${ }^{32}$.

En vista de la continua denegación del acceso a la ayuda humanitaria, el Consejo de Seguridad, en su Resolución 2165 (2014) adoptada por unanimidad, autorizaba por primera vez a las agencias de la ONU a llevar a cabo las actividades humanitarias en Siria desde los países vecinos sin necesidad de consentimiento por parte del gobierno de Siria y solo requiriendo una notificación a las autoridades sirias ${ }^{33}$. A pesar de la adopción de estas resoluciones del Consejo de Seguridad, de carácter obligatorio para los Estados miembros de la ONU, «las partes en el conflicto continuaron restringiendo totalmente o en gran medida el acceso a las zonas sitiadas» $\mathrm{y}$ «las injerencias y restricciones deliberadas de las partes continuaron impidiendo la prestación de ayuda» ${ }^{34}$. En definitiva, las resoluciones fueron ignoradas por las partes en conflicto y los demás Estados miembros de la ONU, duplicándose en número de personas necesitadas y disminuyendo la ayuda humanitaria ${ }^{35}$. Además, se ha dado la paradoja de que en Siria los inspectores de armas químicas han tenido libre acceso sobre la base de la resolución 2118 (2013) del Consejo de Seguridad, mientras que las ambulancias, los alimentos y los medicamentos de las organizaciones humanitarias se han visto sistemáticamente obstaculizados ${ }^{36}$.

30 Consejo de Seguridad, Resolución 2042 (2012), de 14 de abril, párr. 10. Véase también, AsAMBlea General, La situación en la República Árabe Siria, Resolución 66/253, de 16 de febrero de 2012, párr. 10 .

31 Véase, entre otras, CONSEJo de SEguridad, Resolución 2139 (2014), de 22 de febrero; Resolución 2165 (2014), de 14 de julio; Resolución 2191 (2014), de 17 de diciembre, y Resolución 2258 (2015), de 22 de diciembre.

32 Consejo de SEguridad, Resolución 2258 (2015), op. cit., nota 32.

33 Consejo de SEguridad, Resolución 2165 (2014), op. cit., nota 32, párr. 2.

34 Informe del Secretario General sobre la aplicación de las resoluciones del Consejo de Seguridad 2139 (2014), 2165 (2014) y 2191 (2014), ONU Doc. S/2015/962, de 11 de diciembre de 2015, párrs. 33 y 43 .

35 Norwegean Refugee Council, Failing Syria: Assessing the impact of the UN Security Council Resolutions in protecting and assisting civilians in Syria, 2015.

${ }^{36}$ MÉdecins Sans Frontière, Political will shown to work for chemical weapons access in Syria - same now needed urgently for humanitarian aid, 15 de octubre de 2013, disponible en el siguiente enlace: http://www.msf.org/article/political-will-shown-work-chemical-weapons-access-syria-\%E2\%80\%93same-now-needed-urgently (consultada el 20 de octubre de 2016). 
Según el último informe de la Comisión Internacional Independiente de Investigación en Siria establecida por las Naciones Unidas, aproximadamente 4,5 millones de sirios están confinados en zonas en donde los actores humanitarios no tienen acceso regular ${ }^{37}$. El asedio de ciudades como Alepo, Madaya, Zabadani o Bqine, en las que se impide el acceso de la ayuda humanitaria, conlleva la vulneración del derecho a una alimentación adecuada, a la salud y a la vida a la población civil, lo cual constituye la violación de derechos humanos fundamentales y de obligaciones que emanan del Derecho internacional de los derechos humanos y del Derecho internacional humanitario. Igualmente, la Comisión ha denunciado los ataques indiscriminados y desproporcionados que sufre la población civil en Siria, en donde las fuerzas gubernamentales, los grupos armados de la oposición y los grupos terroristas utilizan los asedios y la consecuente hambruna, la denegación del acceso a la ayuda humanitaria y otras formas de privación como métodos de guerra para forzar la rendición o extraer concesiones políticas ${ }^{38}$.

En este sentido, el consentimiento de las partes en conflicto para el acceso de la ayuda humanitaria no puede denegarse por razones arbitrarias, de modo que si la población civil no está suficientemente dotada de suministros esenciales para su supervivencia, la parte responsable de cubrir estas necesidades no proporciona la asistencia necesaria y hay organizaciones humanitarias que actúan sobre la base de los principios de humanidad e imparcialidad que han ofrecido sus servicios, la parte está obligada a dar su consentimiento ${ }^{39}$. La denegación del acceso de la ayuda humanitaria se puede considerar arbitraria cuando contribuye a hacer padecer hambre a la población civil -véase sección 2.2-; cuando no permite que las operaciones de asistencia médica traten a los combatientes de la parte enemiga; cuando la denegación de la ayuda humanitaria es utilizada como castigo colectivo para la población civil; cuando la denegación se realiza respecto a un grupo determinado o una parte de la población civil lo cual constituye una violación de la prohibición de discriminación; o bien cuando la obstaculización de la ayuda humanitaria vulnera derechos humanos aplicables en tiempo de conflicto armado como, por ejemplo, cuando impide garantizar el contenido esencial de los derechos económicos, sociales y culturales, como el derecho a un nivel de vida adecuado o derecho a la salud ${ }^{40}$. En todo caso, las consecuencias de la denegación del acceso de la ayuda humanitaria de forma arbitraria implican una vulneración del Derecho internacional de los derechos humanos y del Derecho internacional humanitario, lo cual conlleva la responsabilidad internacional del Estado.

37 Consejo de Derechos Humanos, Report of the Independent International Commission of Inquiry on the Syrian Arab Republic, UN Doc. A/HRC/31/68, de 11 de febrero de 2016, párr. 118.

38 Ibid., párr. 146.

39 Henckaerts, J.-M. y Doswald-Beck, L., op. cit., nota 25, norma 55; OcHA, op. cit., nota 24, p. 21; Pilloud, C. et al. (eds.), Commentary on the additional protocols: of 8 June 1977 to the Geneva Conventions of 12 August 1949, Ginebra, Martinus Nijhoff Publishers, 1987, párr. 2805.

40 OCHA, op. cit., nota 24, pp. 23-24. 


\subsection{Hambruna como arma de guerra}

En el marco de la regulación jurídica internacional, el Derecho internacional humanitario prohíbe hacer padecer hambre a la población civil como método de guerra, tanto en conflicto armado internacional como de carácter interno:

«Queda prohibido, como método de combate, hacer padecer hambre a las personas civiles. En consecuencia, se prohíbe atacar, destruir, sustraer o inutilizar con ese fin los bienes indispensables para la supervivencia de la población civil, tales como los artículos alimenticios y las zonas agrícolas que los producen, las cosechas, el ganado, las instalaciones y reservas de agua potable y las obras de riego» ${ }^{41}$.

Si bien los Convenios de Ginebra de 1949 tienen un carácter universal al estar ratificados por la práctica totalidad de los Estados, sus Protocolos adicionales no gozan de tan amplia aceptación. No obstante, en la actualidad, se considera que la prohibición de hacer padecer hambre como método de guerra, tanto en conflicto armado internacional como interno, forma parte también del Derecho internacional humanitario consuetudinario ${ }^{42}$ y, por tanto, es obligatorio para todos los Estados, aunque no sean parte de los Protocolos Adicionales.

Asimismo, la Corte Penal Internacional (CPI) tiene competencia sobre crímenes de guerra cometidos en conflictos armados internacionales, en particular cuando se cometan como parte de un plan o política o como parte de la comisión en gran escala de tales crímenes, entre los cuales se incluye «hacer padecer intencionalmente hambre a la población civil como método de hacer la guerra, privándola de los objetos indispensables para su supervivencia, incluido el hecho de obstaculizar intencionalmente los suministros de socorro de conformidad con los Convenios de Ginebra» ${ }^{43}$. Sin embargo, el Estatuto no contempla hacer padecer hambre como un crimen de guerra en conflictos armados internos. En todo caso, el Estatuto de Roma prevé también como crimen de lesa humanidad el ataque sistemático o generalizado dirigido contra la población civil y con conocimiento de dicho ataque, entre otros, el exterminio entendido como «la imposición intencional de condiciones de vida, entre otras, la privación del acceso a alimentos o medicinas, entre otras, encaminadas a causar la destrucción de parte de una población» ${ }^{44}$.

En relación a los asedios, el Derecho internacional humanitario no los prohíbe siempre que tengan por finalidad alcanzar un objetivo militar y no hacer padecer hambre a la población civil ${ }^{45}$. Igualmente, en caso de embar-

\footnotetext{
41 Art. 14 del Protocolo Adicional II. Véase, también, el art. 54.1 del Protocolo Adicional I.

42 Henckaerts, J.-M. y Doswald-Beck, L., op. cit., nota 25, norma 53.

43 Conferencia Diplomática de Plenipotenciarios de las Naciones Unidas sobre el establecimiento de una Corte Penal Internacional, ONU Doc. A/CONF.183/9, de 17 de julio de 1998, art. 8.2.b.xxv).

44 Estatuto de Roma, art. 7.1.b) y 7.2.b).

45 HencKaerts, J.-M. y Doswald-Beck, L., op. cit., nota 25, pp. 209-210.
} 
gos o asedios que provocan hambruna, las partes en conflicto deberán facilitar el paso de la ayuda humanitaria si la población civil no está suficientemente abastecida. Respecto al asedio de determinadas zonas de Siria, el Consejo de Seguridad ha exigido «que todas las partes permitan la prestación de asistencia humanitaria, incluida la asistencia médica, dejen de privar a los civiles de alimentos y medicinas indispensables para su supervivencia y permitan la evacuación rápida, segura y sin trabas de todos los civiles que deseen abandonar esos lugares» siendo necesario que las partes establezcan "pausas humanitarias, días de tranquilidad, alto el fuego localizados y treguas para que los organismos humanitarios tengan acceso seguro y sin trabas a todas las zonas afectadas» ${ }^{46}$.

Junto a la prohibición de hacer padecer hambre a la población civil como método de guerra, el Derecho internacional humanitario establece que las partes en conflicto deberán permitir y facilitar el paso rápido y sin trabas de toda ayuda humanitaria destinada a la población civil necesitada ${ }^{47} \mathrm{y}$, además, garantizar la libertad de movimiento del personal humanitario autorizado, pudiendo ser restringida temporalmente en caso de necesidad militar imperiosa ${ }^{48}$.

En todo caso, el Derecho internacional humanitario busca un equilibrio entre las necesidades militares y las humanitarias, siendo el Estado el primer responsable de cubrir las necesidades básicas de la población afectada por el conflicto $\operatorname{armado}^{49}$. Las operaciones humanitarias requieren el consentimiento de las partes y, para que no puedan ser consideradas una injerencia en los asuntos internos del Estado, deben ser realizadas sobre la base de los principios de imparcialidad, neutralidad e independencia ${ }^{50}$. La denegación del acceso a la ayuda humanitaria no puede ser arbitraria, y, en cualquier caso, si provoca hambruna no existe una razón válida para denegar dicho acceso.

\subsection{Aumento de la violencia contra las operaciones de ayuda humanitaria}

Desde 2002, el número de personas pertenecientes a organizaciones humanitarias muertas o heridas se ha triplicado, llegando en el 2013 a la cifra de 474 personas, afectando aproximadamente al 90 por 100 de los casos

46 Consejo de SEguridad, Resolución 2139 (2014), op. cit., nota 32, párr. 5.

47 Véanse el art. 23 del IV Convenio de Ginebra de 12 de agosto de 1949 y el art. 70.2 del Protocolo Adicional I. Nótese que el Protocolo Adicional II se refiere a «acciones de socorro» y no expresamente al acceso a la ayuda humanitaria, estableciendo en su art. 18.2 que «cuando la población civil esté padeciendo privaciones extremadas por la falta de abastecimientos indispensables para su supervivencia, tales como víveres y suministros sanitarios, se emprenderán, con el consentimiento de la Alta Parte Contratante interesada, acciones de socorro en favor de la población civil, de carácter exclusivamente humanitario e imparcial y realizadas sin distinción alguna de carácter desfavorable» (cursiva añadida).

48 Art. 71.3 del Protocolo Adicional I y art. 18.2 del Protocolo Adicional II.

49 Schwendimann, F., "The legal framework of humanitarian access in armed conflict», International Review of the Red Cross, vol. 93, 2011, núm. 884, pp. 1006-1007.

${ }_{50}$ Military and paramilitary activities in and against Nicaragua (Merits), Judgment, ICJ Reports 1986, párr. 241. 
a personal nacional de organizaciones internacionales o locales, incluyendo personal y voluntariado de las Sociedades Nacionales de la Cruz Roja y Media Luna Roja ${ }^{51}$. La razón por la cual el personal nacional es el más afectado es porque se encuentra en la primera línea en el terreno y está en contacto directo con los grupos armados. En otras ocasiones, el personal humanitario nacional es objeto de violencia porque proviene de otra zona o tiene un origen étnico diferente de la población local a la que atiende ${ }^{52}$. Los contextos en los que el personal humanitario está más expuesto a la violencia son Afganistán, Siria, Sudán del Sur, República Centroafricana y Paquistán, siendo los secuestros, por encima de los disparos, la forma más habitual de violencia ejercida contra el personal humanitario ${ }^{53}$.

En Siria los principales obstáculos a la ayuda humanitaria médica son la violencia y la inseguridad, los ataques a las instalaciones y personal médico y la ausencia de autorización por parte del gobierno y el incumplimiento por parte de los grupos armados de las garantías de seguridad de los equipos de la organización ${ }^{54}$. Esto ha llevado a que organizaciones como MSF se hayan visto obligadas a retirar todo su personal expatriado de la zona y cerrar cuatro centros de salud de las áreas bajo control del ISIS, cambiando su modus operandi y, por tanto, trabajando solo con personal local para poder seguir prestando asistencia médica y humanitaria ${ }^{55}$.

Asimismo, en la República Centroafricana en varias ocasiones el personal médico de MSF tuvo que proteger a los pacientes de los ataques de los grupos armados dentro de los hospitales ${ }^{56}$. Por otra parte, en Sudán, durante 2015 continuó interrumpido el acceso humanitario en las zonas de conflicto no controladas por el gobierno, además de las restricciones administrativas relativas a las autorizaciones de viajes y emisión de visados para el personal humanitario que siguieron dificultando las actividades de ayuda humanitaria ${ }^{57}$. Ya en 2009, el gobierno del Sudán había expulsado a 13 ONG internacionales y revocado las licencias de tres ONG nacionales (afectando a 7.610 agentes humanitarios) que operaban en la zona del Darfur, coincidiendo con la emisión de la orden de arresto contra el Presidente sudanés Omar Al-Bashir por crímenes de guerra y crímenes de lesa humanidad de la $\mathrm{CPI}^{58}$, seguramente

51 FICR, Informe mundial de desastres-resumen: los agentes locales en el centro de la acción humanitaria eficaz, 2015, p. 27.

52 MaXwell, D. y Donnelly, P., Component 2. The contemporary Humanitarian Landscape: Malaise, Blockages and Game Changers. Case Study: The Violence in South Sudan, December 2013 to Present, agosto de 2015, p. 16.

53 Humanitarian Outcomes, Aid Worker Security Report 2015. Figures at a glance, disponible en https://aidworkersecurity.org/sites/default/files/HO_AidWorkerSecPreview_1015_G.PDF (consultada el 20 de octubre de 2016).

54 Médecins Sans Frontière, International Activity Report, 2014, p. 82.

55 Ibid.

56 Ibid., p. 6.

57 Informe del Secretario General sobre la protección de los civiles en los conflictos armados, ONU Doc. S/2016/447, de 13 de mayo de 2016, párr. 30.

58 BARBER, R., «Facilitating humanitarian assistance in international humanitarian and human rights law», International Review of the Red Cross, vol. 91, 2009, núm. 874, pp. 371-397, p. 377. Véase 
por considerar que eran testimonios incómodos de las atrocidades que se cometían en el conflicto armado.

Uno de los motivos principales por los que el personal humanitario y médico es objeto de ataques y violencia es por la percepción de parcialidad que tienen las diferentes partes en conflicto ${ }^{59}$. En Siria, por ejemplo, MSF denunció los ataques continuos sufridos por parte de las fuerzas de seguridad del Gobierno de Bashar al Assad en los centros de salud ubicados en zonas controladas por la oposición por considerar que el personal médico era afín o simpatizante con la oposición. En este contexto, atenerse a los principios humanitarios es lo que permite a las organizaciones humanitarias preservar el espacio humanitario ${ }^{60}$.

El problema es que a menudo la ayuda humanitaria internacional se confunde con otras intervenciones internacionales de tipo militar, ya se trate de una misión de paz, una intervención en virtud de la «responsabilidad de proteger» o una intervención no autorizada por las Naciones Unidas llevada a cabo por una coalición de Estados (como en el caso de Iraq, Afganistán o Siria). Esto es porque las partes en conflicto perciben la intervención internacional como un todo, sin distinguir la ayuda humanitaria respecto a los demás tipos de intervención, lo cual puede afectar negativamente a las actividades humanitarias ${ }^{61}$. Además, esta distinción cada vez más difusa entre actividades humanitarias y militares también repercute en la percepción de neutralidad de las agencias humanitarias que pueden perder su credibilidad y aceptación como actores que tienen motivaciones puramente humanitarias y no de tipo político ${ }^{62}$.

En el conflicto de Afganistán, por ejemplo, Estados Unidos desarrolló tres roles a la vez: fue una parte beligerante, fue el mayor donante en ayuda humanitaria y al mismo tiempo proveedor directo de asistencia humanitaria ${ }^{63}$. Esta confusión de roles contribuyen, sin duda, a la percepción de "parcialidad» de las actividades humanitarias por parte de la población en general y de los diferentes grupos armados. Además, en el caso de Afganistán USAID (United States Agency for International Development) descubrió en el 2010 que los afganos subcontratados pagaban una "protection tax» a los líderes

también, EcKRoth, K. R., «Humanitarian principles and protection dilemmas: Addressing the security situation of aid workers in Darfur», Journal of International Peacekeeping, vol. 14, 2010, núms. 1-2, pp. 86-116, p. 100.

59 Schwendimann, F., op. cit., nota 50, p. 994.

${ }^{60}$ Médecins Sans Frontière, Syria: Aleppo surviving on a fragile humanitarian lifeline. The brutal violence against the medical mission has put the healthcare System on the verge of collapse, 15 de marzo de 2015, disponible en el siguiente enlace: $h t t p: / / w w w . m s f . o r g / a r t i c l e / s y r i a-a l e p p o-s u r v i v i n g-f r a g i l e-h u-$ manitarian-lifeline (consultada el 20 de octubre de 2016).

61 Hofman, M., "The Evolution from Integrated Missions to "Peace Keepers on Steroids" ", Global Responsibility to Protect, vol. 2, 2014, núm. 6, p. 247.

62 JAEGER, T., «Humanitarian and Military Action in Armed Conflict-Side by Side, not Hand in Hand», Nordic Journal of International Law, vol. 78, 2009, núm. 4, pp. 567-579, p. 573.

63 Seybolt, T., "Harmonizing the Humanitarian Aid Network: Adaptive Change in a Complex System», International Studies Quarterly, vol. 53, 2009, núm. 4, p. 1046. 
locales talibanes que alcanzaba un 20 por 100 de las tasas administrativas, llegando a un total estimado de 5,4 millones de dólares ${ }^{64}$, lo cual demuestra que a menudo las agencias humanitarias deben pagar tasas o sobornos en los puntos de control o a los líderes locales para poder operar y prestar asistencia.

Asimismo, en un contexto de conflicto armado en el que población civil está en riesgo, distintos actores internacionales pueden adoptar medidas para protegerla, siendo importante que las operaciones que impliquen a las fuerzas armadas (por ejemplo, la creación de zonas seguras o evacuación de la población) tengan en cuenta el impacto que pueden tener sus acciones en las operaciones humanitarias. En este sentido, es importante procurar que las operaciones militares no tengan un efecto negativo en la percepción de la neutralidad de las agencias humanitarias por parte de los grupos armados y la población civil para evitar que pongan en peligro la seguridad de los actores humanitarios ${ }^{65}$.

\section{EL ROL CRECIENTE DE LOS AGENTES LOCALES EN LOS CONFLICTOS ARMADOS PROLONGADOS}

La obstaculización constante de la ayuda humanitaria junto con el aumento de la violencia contra el personal humanitario en conflictos armados prolongados en los que las agencias internacionales humanitarias no pueden intervenir directamente y lo tienen que hacer a través de agentes locales, ha planteado numeroso retos, entre los que cabe destacar la necesidad de un mayor comprensión del contexto y las distintas dinámicas de poder entre las partes en conflicto y la integración de la ayuda humanitaria en iniciativas más amplias dirigidas a abordar las causas estructurales del conflicto. En escenarios como Siria, la «respuesta local», ha sido fundamental para cubrir las necesidades de la población civil, ante el vacío producido por la obstaculización del acceso de las agencias humanitarias internacionales. Desde el inicio del conflicto en el 2011 entre 600 y 700 ONG se han establecido en Siria y cerca de 30 organizaciones de diáspora se han registrado en Estados Unidos, Europa, Turquía o en los Estados del Golfo, trabajando de forma independiente o como contrapartes de ONG internacionales ${ }^{66}$.

${ }^{64}$ GaLLI, A. «The US Humanitarian Assistance Facilitation Act», Journal of International Humanitarian Legal Studies, vol. 5, 2014, núms. 1-2, pp. 130-151, p. 140.

65 ICRC e INTERACTION, Outcome report: Trapped in Conflict: Evaluating Scenarios to Assist AtRisk Civilians, International Committee of the Red Cross and InterAction Roundtable, julio de 2015.

${ }_{66}$ Svoboda, E. y Pantuliano, S., «International and local/diaspora actors in the Syria response. A diverging set of systems?», HPG Working Paper, marzo de 2015, p. 10. Para estos autores la «respuesta local» comprende a grupos y organizaciones que no pertenecen al sistema humanitario tradicional de las Naciones Unidas, el MICR y MLR o las ONG internacionales, y que comprende colectivos profesionales como los médicos que ya existían antes del conflictos, organizaciones de la caridad, redes antigobierno y activistas, organizaciones de la diáspora, redes de coordinación y grupos armados que también proveen asistencia. 
En consecuencia, con el objeto de mejorar la eficacia de la ayuda humanitaria en contextos de conflictos armados prolongados, se plantea la necesidad de incorporar a los agentes locales dándoles mayor protagonismo y no como meros vehículos de asistencia humanitaria. Para ello se analizará cómo deberían coordinarse con las agencias humanitarias internacionales, a continuación se planteará la dificultad de financiar a los agentes locales en un sistema dominado por los principales donantes occidentales y, finalmente, se abordará la necesidad de fomentar la capacidad local mediante estrategias de actuación a largo plazo.

\subsection{La necesidad de incorporar a los agentes locales en la ayuda humanitaria y su relación con las agencias humanitarias internacionales}

En los conflictos armados prolongados, los agentes locales pueden contribuir a una mayor eficacia de la ayuda humanitaria no solo por su proximidad sino también por su perspectiva y mejor conocimiento del entorno, la posibilidad de permanecer en el terreno mayor tiempo que las agencias internacionales y la capacidad de llegar a población que está fuera del alcance de los actores internacionales ${ }^{67}$. No obstante, tampoco se puede transferir a los actores locales toda la responsabilidad ante las crisis humanitarias y convertirlos en un mero vehículo de la ayuda humanitaria internacional ${ }^{68}$ sino que debe haber un mayor equilibrio de responsabilidad entre las agencias humanitarias internacionales y las nacionales/locales mediante un acuerdo de asociación como contraparte ${ }^{69}$.

Si bien los agentes locales y los grupos de diáspora gozan de mayor acceso a las personas necesitadas respecto a las agencias internacionales humanitarias, no siempre es una tarea fácil. El personal sirio de las ONG locales suele pertenecer a las mismas comunidades que los grupos armados y, por tanto, tienen una posición privilegiada para negociar con ellos el acceso de la ayuda humanitaria. Sin embargo, no necesariamente el personal local está más seguro que el personal internacional de las agencias internacionales humanitarias ${ }^{70}$. El caso de Sudán del Sur demuestra que, contrariamente a lo que se cree, el personal humanitario internacional objeto de violencia apenas alcanza un 10 por 100, siendo el personal nacional el que mayoritariamente sufre ataques por parte de los diferentes grupos $\operatorname{armados}^{71}$.

67 Véanse, entre otros, SwITHERn, S., Global Humanitarian Assistance Report 2015, Londres, Development Initiatives, p. 74; y FICR, Informe mundial de desastres 2015-resumen: los agentes locales en el centro de la acción humanitaria eficaz.

68 World Humanitarian Summit, Regional Consultation Europe and Others Group, febrero de 2015, p. 6.

69 Svoboda, E. y Pantuliano, S., op. cit., nota 66, p. 2.

70 Ibid., p. 12.

71 MaXwell, D. y Donnelly, P., op. cit., nota 52, p. 16. 
Cuando el acceso de la ayuda humanitaria está obstaculizado o la inseguridad del personal humanitario es muy elevada, las agencias internacionales suelen optar por la «gestión a distancia» de la crisis humanitaria, como por ejemplo, en el caso de MSF en Siria. En estas situaciones, normalmente la responsabilidad recae en el ámbito internacional y la dotación de personal local varía en función de la inseguridad aunque también puede ocurrir que el diseño del proyecto prevea directamente la ejecución en la distancia como ha ocurrido en el caso de Somalia, en donde los proyectos se dirigen, por lo general, desde Kenia. Dentro de las distintas formas de colaboración con los actores locales, las agencias internacionales pueden subcontratar la prestación de servicios humanitarios con empresas locales; pueden apoyar las actividades de socorro en efectivo o en especie; puede consistir en un intercambio de información, ideas y recursos; en la organización de cursos de formación o en el fomento de la capacidad local ${ }^{72}$.

El problema es que esta gestión a distancia suele considerarse una medida de carácter temporal y se adopta en respuesta a la inseguridad de la zona, lo cual hace que los organismos internacionales no estén interesados en destinar recursos para diseñar políticas y directrices más a largo plazo. La gestión a distancia también implica que las agencias humanitarias son percibidas como «distantes» respecto a la población afectada, trasladando las decisiones fuera del terreno en donde están las necesidades reales ${ }^{73}$. Además, la relación de poder entre los agentes internacionales y los agentes locales es desigual, distinguiéndose diferentes formas de gestión a distancia o remota ${ }^{74}$ : el "control remoto» en el que las agencias internacionales adoptan todas las decisiones programáticas con una escasa delegación de autoridad a las agencias locales; el «soporte remoto» con una delegación parcial o temporal del poder de decisión a los actores locales; y finalmente la «asociación remota» en la que las agencias internacionales y las locales están al mismo nivel, trasladando una parte importante de la responsabilidad a los actores locales.

Asimismo, la presencia en el terreno antes de la crisis puede facilitar la cooperación con los agentes locales, como es el caso del MICR y MLR que tiene la ventaja de contar con Sociedades Nacionales en prácticamente todos los países del mundo, lo cual permite al CICR actuar con una contraparte que conoce el terreno y que además actúa conforme a los principios de humanidad, imparcialidad, neutralidad e independencia ${ }^{75}$. En todo caso, cada vez más las agencias internacionales son conscientes de que la gestión a distancia no es

72 FICR, Informe mundial de desastres 2015-resumen: los agentes locales en el centro de la acción humanitaria eficaz, p. 31.

73 CARTER, W., Component 2: Enabling access and quality aid in insecure environments, Secure Access in Volatile Environments (SAVE), agosto de 2015, p. 10.

${ }^{74}$ HaRmer, A., "Remote partnership: aid delivery in insecure environments», en FICR, World Disasters Report 2015, p. 125.

75 En la actualidad cuenta con 190 Sociedades Nacionales de la Cruz Roja y de la Media Luna Roja. Para más información, consultar en siguiente enlace: http://www.ifrc.org/en/who-we-are/the-movement/. 
una cuestión temporal sino que va a constituir una forma indispensable de trabajar sobre todo en conflictos armados prolongados en los que se deniega el acceso a la ayuda humanitaria y las agencias internacionales no pueden operar directamente.

\subsection{La financiación insuficiente de los agentes locales}

Uno de los retos de la ayuda humanitaria es la llamada «brecha de financiación humanitaria» que se estima en 15 billones de dólares ${ }^{76}$. Teniendo en cuenta que en la actualidad la comunidad internacional destina cerca de 25 billones de dólares para cubrir las necesidades de las personas como consecuencia de los conflictos armados o desastres naturales y siendo esta cantidad doce veces mayor que hace cincuenta años, sigue sin ser suficiente para atender al número creciente de personas que necesitan ayuda humanitaria. De modo que terminar con esta brecha significaría "no one having to die or live without dignity for the lack of money» ${ }^{77}$. Para ello, el Panel de Alto Nivel sobre la Financiación Humanitaria estima que hay que reducir las necesidades, movilizar más fondos a través de los canales tradicionales o mecanismos innovadores y mejorar la eficiencia de la asistencia humanitaria.

Las agencias humanitarias de la ONU y las ONG internacionales más grandes junto con el MICR y MLR reciben la mayor parte de recursos. De hecho, tan solo cinco organizaciones humanitarias (Médecins Sans Frontières, Save the Children, Oxfam, World Vision y el Comité Internacional de Rescate) recibieron el 31 por 100 de los recursos en 2014. Además, los gobiernos normalmente canalizan sus contribuciones a través de organizaciones intergubernamentales como la Unión Europea o la Unión Africana. La financiación privada para conflictos prolongados no alcanza el 10 por 100 y los estudios demuestran que la población general tiende a hacer donaciones más onerosas para desastres naturales y en cambio muestra más reticencia en conflictos armados porque tienen más connotaciones políticas. Los tres principales donantes son Estados Unidos, UE y Reino Unido, que en 2014 aportaron más del 50 por 100 de las contribuciones humanitarias gubernamentales ${ }^{78}$.

La cuestión es que los principales donantes siguen canalizando las contribuciones humanitarias a través de ONG internacionales de su país o agencias de la ONU, de modo que uno de los retos de la ayuda humanitaria es fomentar la financiación directa a ONG nacionales o locales. En 2014, tan solo el 0,2 por 100 de la financiación humanitaria internacional fue enviada directamente a ONG locales y nacionales, y la financiación a los gobiernos directamente afectados apenas recibieron el 3 por 100 de toda la financiación

76 OcHA, «High-Level Panel on Humanitarian Financing», Report to the Secretary-General: Too important to fail - Addressing the humanitarian financing gap, diciembre de 2015.

77 Ibid.

78 Datos extraídos del informe de ALNAP 2015, op. cit., nota 10. 
humanitaria ${ }^{79}$. En este sentido, el Secretario General de las Naciones Unidas en su último informe elaborado para la Cumbre Humanitaria Mundial 2016 reclama «inversión en la humanidad» como una responsabilidad compartida de la comunidad internacional, y propugna fomentar la capacidad local («local capacity-building»). Para ello, el Secretario General pide a las agencias de la ONU que al menos el 15 por 100 de la financiación humanitaria se invierta directamente en ONG locales y nacionales ${ }^{80}$.

En el caso de Siria, en general, las donaciones a las agencias humanitarias internacionales se destinan a campos de refugiados situados fuera del territorio - principalmente en Líbano, Jordania, Turquía o Iraq- bien porque no tienen permiso para trabajar en el país o han tenido que retirar el personal de la zona por razones de inseguridad, o porque cuando trabajan en Siria, sus actividades humanitarias son muy limitadas debido a las restricciones del gobierno $^{81}$. Además, los donantes occidentales, en un primer momento, exigían para financiar a las ONG locales que estas tuvieran al menos tres años de existencia con cuentas auditadas pero, teniendo en cuenta que la mayoría de las ONG y organizaciones de la diáspora se crearon cuando estalló el conflicto, la mayoría no cumplía con estas condiciones y los donantes tuvieron que flexibilizar los criterios para poder financiar agencias en Siria ${ }^{82}$. Otras veces, los donantes imponen limitaciones en la selección de proyectos o de programas, lo cual puede provocar que el personal humanitario no pueda atender a todas las personas necesitadas y se ponga en duda su actuación sobre la base de los principios de imparcialidad y neutralidad, aumentando el riesgo de la seguridad de los agentes humanitarios ${ }^{83}$.

Por otro lado, a veces las ONG locales prefieren recibir dinero en vez de bienes porque logísticamente es más complicado y atrae más la atención y, por tanto, tiene más riesgo. De modo que, si bien los agentes locales están dispuestos a tomar riesgos para transportar medicinas que no están disponibles en el país, en caso de alimentos, prefieren el dinero en efectivo para poderlos comprar en la misma zona ${ }^{84}$. En cambio, las agencias internacionales prefieren enviar bienes en vez de dinero efectivo porque así evitan tener que cumplir con los trámites de las medidas anti-terroristas y de blanqueo de dinero que pueden demorar la ayuda ${ }^{85}$.

Así, USAID requiere a las organizaciones que reciben sus fondos la firma del "Certificado Anti-Terror», en el cual se comprometen a no entregar ningún tipo de material o recursos a personas o entidades relacionadas con actos terroristas y por tanto, prohíbe cualquier tipo de contacto («nocontact policy») con cierto grupos como Hamas, la Yihad islámica o los

\footnotetext{
79 ONU Doc. A/70/709, op. cit., nota 11, p. 43.

Ibid., p. 45.

81 Véase, entre otros, Hand in Hand For Syria en http://www.handinhandforsyria.org.uk/.

82 Svoboda, E. y Pantuliano, S., op. cit., nota 66, p. 18.

3 GALli, A., op. cit., nota 64, p. 139.

84 Svoboda, E. y Pantuliano, S., op. cit., nota 66, p. 17

5 IsmaIL, O., "Guns not hurricanes», World Disasters Report 2015, FICR, p. 163.
} 
Talibanes ${ }^{86}$. No obstante, a veces las organizaciones deben contactar con los líderes locales para obtener su autorización y coordinar la ayuda humanitaria. Como consecuencia de esta restricción, algunas agencias deciden no coordinarse con las autoridades locales o llevar a cabo proyectos más modestos lo cual resta eficacia y sostenibilidad a la ayuda humanitaria ${ }^{87}$.

En todo caso, la financiación internacional de las ONG nacionales y locales es «impredecible, volátil, de difícil acceso, insuficiente y no contribuye suficientemente para apoyar el fortalecimiento de la capacidad» 88 , de modo que se sigue hablando de capacidad local pero sin grandes cambios a nivel de financiación.

\subsection{El fomento de la capacidad local mediante estrategias a largo plazo}

Uno de los problemas de los conflictos armados prolongados es su naturaleza cambiante, lo cual implica que la ayuda humanitaria debe adaptarse constantemente a nuevas emergencias además de las ya existentes en la zona de conflicto. En este sentido, la ONG Hand in Hand for Syria denunciaba el impacto en la población civil de los bombardeos aéreos iniciados por el Reino Unido en diciembre de 2015 porque "we are unable to focus on the long term development of Syria, as long as we are consistently forced to divert our attention on emergency aid efforts and the immediate humanitarian crisis» ${ }^{89}$. Una muestra de ello es el «Syria Regional Response Plan» que combina la asistencia humanitaria con el desarrollo al reconocer que las necesidades a largo plazo deben cubrirse al mismo tiempo que las de corto plazo para los refugiados sirios:

"The increasing stress on local living conditions changed the emphasis within the RRP6 planning due to a mounting realization that adequate refugee protection cannot be maintained without enhancing social cohesion and addressing investment in local infrastructure, economy and social systems. The early and unprecedented engagement of development agencies in the Syria refugee emergency also reflects an understanding that longer term, more comprehensive assistance is required to achieve stability and build resilience» ${ }^{90}$.

Además, en este tipo de contextos, en la medida en que las agencias humanitarias no solo tratan los «efectos» sino también las «causas» de los conflictos armados prolongados, la distinción entre actividades «humanitarias» y de «desarrollo» está cada vez más desdibujada. Al principio, la mayoría de agencias mantenían dos agendas separadas, la de emergencias y la de desa-

86 GALLI, A., op. cit., nota 64, p. 134.

87 Ibid., p. 138.

88 ALNAP, op. cit., nota 9, p. 47.

89 Hand In Hand For Syria, Statement on British Air Strikes in Syria, 3 de diciembre de 2015, disponible en el siguiente enlace: http://www.handinhandforsyria.org.uk/britain-statement-3rd-december2015/\#sthash.j3Wa8jWQ.dpuf (consultada el 20 de octubre de 2016).

90 Acnur, 2014 Syria Regional Response Plan Strategic Overview, p. 16 (redonda añadida). 
rrollo, pero la creciente inseguridad y prolongación de los conflictos armados ha hecho más difícil distinguir entre lo que constituye gastos y actividades humanitarias de los gastos y actividades de desarrollo ${ }^{91}$.

No obstante, cuando en este tipo de contextos se habla del «fomento de la capacidad local», para algunas organizaciones es una cuestión tabú porque equivale a realizar actividades de desarrollo, es decir, acciones típicas de organizaciones que trabajan a largo plazo en la zona y no propias de organizaciones humanitarias que responden a emergencias puntuales ${ }^{92}$. No es el caso de las ONG del Sur que no tienen ningún problema en combinar proyectos a corto y largo plazo y de hecho critican a las ONG del Norte por querer separar ambas cuestiones ${ }^{93}$. Si bien el fomento de la capacidad local es una cuestión que tradicionalmente se ha trabajado en los programas de desarrollo de las agencias internacionales, también es cierto que esta actividad se ha vuelto inseparable de la acción humanitaria de todas las organizaciones humanitarias y que este enfoque se considera actualmente indispensable para una mayor eficacia de la ayuda humanitaria.

Teniendo en cuenta que los conflictos armados se prolongan durante años, los expertos apuestan por trabajar con proyectos plurianuales y a largo plazo y no anuales, como es la práctica habitual en los proyectos humanitarios, y dejar de lado el debate entre humanitario y desarrollo y centrarse en las personas necesitadas en contextos de crisis. Según el Secretario General, el nuevo paradigma de la asistencia humanitaria internacional, llevada a cabo por las agencias de la ONU, las ONG y los donantes, viene marcado por tres cambios fundamentales: «a) reforzar los sistemas nacionales y locales en lugar de sustituirlos; $b$ ) prever las crisis en lugar de esperarlas; $c$ ) superar la división entre las actividades humanitarias y de desarrollo, trabajando para lograr resultados colectivos, sobre la base de la ventaja comparativa y en función de calendarios multianuales» ${ }^{94}$.

De modo que, para fomentar la capacidad local en conflictos armados prolongados, las agencias internacionales no deben crear estructuras paralelas sino que deben esforzarse para apoyar a las agencias locales, y nacionales, proporcionarles conocimiento, experiencia y buenas prácticas. El desarrollo de las actividades de forma conjunta y con planes plurianuales contribuye al respeto de la dignidad y el deseo de las personas de ser resilientes, a reducir la dependencia respecto de la asistencia humanitaria extranjera y permite evitar intervenciones internacionales costosas a más largo plazo ${ }^{95}$. Además,

91 Borton, J., Future of the Humanitarian System: Impacts of Internal Changes, Feinstein international Center, HFP, King's College London, Tufts University, 2009, p. 5; y BENNET, Ch., Time to let go. Remaking humanitarian action for modern era, Humanitarian Policy Group, abril de 2016, p. 9.

${ }_{92}$ AUdET, F., «What future role for local organizations? A reflection on the need for humanitarian capacity-building», International Review of the Red Cross, vol. 93, 2011, núm. 884, p. 1154.

93 BINDER, A. y MEIER, C., «Opportunity knocks: why non-Western donors enter humanitarianism and how to make the best of it», International Review of the Red Cross, vol. 93, 2011, núm. 884, p. 1140.

94 ONU Doc. A/70/709, op. cit., nota 11, párr. 110.

95 Ibid., párr. 112. 
en lugares como Somalia, Sudán o Yemen, en donde se ha llevado a cabo una planificación humanitaria multianual, en lugar del ciclo habitual de doce meses, esto ha permitido una base de recursos más estable y la capacidad de desarrollar la resiliencia de los programas en escenarios en los que la ayuda humanitaria será necesaria durante varios años ${ }^{96}$.

\section{LA CUMBRE HUMANITARIA MUNDIAL: COMPROMISOS ADQUIRIDOS PARA EL EMPODERAMIENTO DE LOS AGENTES LOCALES}

A pesar de que la ayuda humanitaria alcanza cada vez a más personas y cuenta con mayores recursos, sigue siendo insuficiente para hacer frente a las crecientes necesidades y retos que plantean los conflictos armados actuales, los desastres naturales, el cambio climático y las crisis humanitarias. Es por este motivo que el Secretario General de las Naciones Unidas decidió convocar la Primera Cumbre Humanitaria Mundial en Estambul del 23 al 24 de mayo de 2016 en donde se reunieron representantes de los Estados miembros, las ONG, la sociedad civil, personas afectadas por las crisis humanitarias, organizaciones internacionales y el sector privado con el objeto de mejorar la eficacia de la ayuda humanitaria. Para preparar la Cumbre se llevaron a cabo consultas regionales a más de 23.000 personas de 153 países durante los tres años anteriores ${ }^{97}$.

Después de este proceso de consulta, el Secretario General propuso una Agenda Humanitaria ${ }^{98}$ en su informe presentado en febrero de 2016 bajo el título "Una humanidad: nuestra responsabilidad compartida», en la que estableció cinco «responsabilidades compartidas»: 1) liderazgo político para prevenir los conflictos y ponerles fin; 2) defender las normas que protegen a la humanidad; 3) no dejar a nadie atrás; 4) cambiar la vida de las personas, desde proporcionar ayuda hasta poner fin a la necesidad, y 5) invertir en humanidad ${ }^{99}$. De las diferentes «responsabilidades compartidas», la cuarta es la que se refiere específicamente a la importancia de la participación y liderazgo de los agentes locales en la gestión de las crisis humanitarias.

Así, para el Secretario General, la cuarta «responsabilidad compartida» implica reforzar los sistemas locales, anticiparse a las crisis y superar la división entre las actividades humanitarias y de desarrollo, y para ello considera indispensable "comprometerse a trabajar a un nivel tan local como sea posible y tan internacional como sea necesario» ${ }^{100}$. En este sentido, la Cumbre

96 AlnAP, op. cit., nota 10, p. 47.

97 Para más información, véase Secretaría de la Cumbre Mundial Humanitaria, Recuperar la humanidad: Síntesis del proceso de consulta para la Cumbre Mundial Humanitaria, Nueva York, Naciones Unidas, 2015.

98 Para más información, véase http://agendaforhumanity.org/ (consultada el 20 de octubre de 2016).

99 ONU Doc. A/70/709, op. cit., nota 11.

100 Ibid., p. 34. 
Humanitaria Mundial marcó una nueva forma de trabajar y supuso un punto de inflexión sobre la participación, capacitación y financiación de los agentes nacionales y locales al adoptar 399 compromisos para promover el empoderamiento de los agentes humanitarios locales ${ }^{101}$.

Por una parte, en el marco del compromiso llamado «gran pacto» («Grand Bargain»), se acordó canalizar un 25 por 100 de la financiación lo más directa posible a los agentes locales de aquí a $2020^{102}$, lo cual es un aumento considerable teniendo en cuenta que actualmente es del 0,2 por 100. Además, en la Cumbre se reconoció la importancia de la ayuda humanitaria en forma de dinero en efectivo y ONG como Mercy Corps se comprometió a aumentar la asistencia basada en la entrega de dinero efectivo, en un 25 por $100^{103}$.

Asimismo, se adoptó la Carta para el Cambio ("Charter4Change») ${ }^{104} \mathrm{im}$ pulsada por ONG nacionales e internacionales con el objetivo de promover la «localización» de la ayuda humanitaria. Hasta ahora, la Carta ha sido firmada por 29 ONG internacionales ha recibido el apoyo de 150 organizaciones locales y nacionales de 43 países. La Carta reclama principalmente una mayor financiación para las ONG del Sur, una mayor transparencia en la transferencia de recursos a las ONG locales y nacionales para fomentar la confianza de los donantes e intermediarios y una mayor capacitación y liderazgo de los agentes locales. Igualmente, la Carta también alerta del impacto negativo que tiene el reclutamiento de personal local por parte de ONG internacionales o de las Naciones Unidas cuando surge una emergencia porque entonces las ONG locales se quedan sin el personal adecuado en el momento en que más lo necesitan.

También cabe destacar la creación de una Red para el Empoderamiento de la Respuesta Humanitaria ( NNetwork for Empowered Aid Response») compuesta por organizaciones locales y nacionales de África, Asia, Pacífico, Oriente Medio y América Latina y que tiene por objetivo poner de relieve la labor que realizan los agentes locales en las crisis humanitarias y remodelar la ayuda humanitaria para pasar de «top-down» a una ayuda «locally driven and owned» ${ }^{105}$. En el pasado, la colaboración entre ONG del Sur primero tenían que ir del Sur al Norte y después del Norte al Sur, mientras que ahora se busca una nueva forma de colaborar dentro del sistema humanitario, para que sea posible también una colaboración entre ONG del Sur sin necesidad de acudir primero a las ONG del Norte. Además, la Red «NEAR» quiere pro-

101 Secretario General, Resultados de la Cumbre Humanitaria Mundial, Informe del Secretario General, ONU Doc. A/71/353, de 23 de agosto de 2016, párr. 36.

102 Ibid., párr. 37.

103 World Humanitarian Summit, Commitments to Action, 8 de septiembre de 2016, disponible en https://www.worldhumanitariansummit.org/sites/default/files/media/WHS\%20Commitment\%20to\%20 Action_8September2016.pdf (consultada el 20 de octubre de 2016).

${ }_{104}$ Disponible en https://charter4change.files.wordpress.com/2016/02/charter-for-change-july-20152. $p d f$ (consultada el 20 de octubre de 2016).

105 Para más información, véase el siguiente enlace: http://www.near.ngo/ (consultada el 20 de octubre de 2016). 
mover una relación justa, equitativa y digna entre los agentes locales y las agencias internacionales, y no de subordinación como ocurre a menudo, y asegurar, al mismo tiempo, que los agentes locales puedan participar en todos los niveles de gestión de las crisis humanitarias para que la ayuda humanitaria sea más efectiva y llegue a las personas que lo necesitan.

Finalmente, respecto a la necesidad de superar la distinción entre actividades humanitarias y de desarrollo, la Cumbre culminó con un compromiso para cambiar la forma en que colaboran los agentes humanitarios y de desarrollo. Así, dentro de los Compromisos para la Acción, el Secretario General junto con siete agencias de las Naciones Unidas y el apoyo del Banco Mundial y de la Organización Internacional para las Migraciones se comprometieron a implementar una «nueva forma de trabajar» que permita atender a las necesidades inmediatas de las personas y al mismo tiempo reducir el riesgo y la vulnerabilidad trabajando conjuntamente para objetivos comunes y en programas ${ }^{106}$.

\section{CONCLUSIONES}

Las crisis humanitarias actuales como los conflictos armados prolongados, en los que el acceso a la ayuda humanitaria es restringida por las diferentes partes en conflicto y en donde la inseguridad del personal humanitario es muy elevada, han puesto de manifiesto la importancia de contar de forma más significativa con los agentes humanitarios locales para poder atender con mayor eficacia a las necesidades de la población afectada. A menudo, las ONG nacionales y locales son las únicas que tienen acceso a zonas remotas o asediadas y además suelen tener un conocimiento más profundo del contexto y de las relaciones de poder entre las distintas partes en conflicto. El problema es que la financiación de la ayuda humanitaria está concentrada en unos pocos donantes occidentales quienes mayoritariamente canalizan sus aportaciones a través de las agencias de la ONU, las ONG internacionales y del MICR y MLR.

Para poder romper con este esquema «tradicional» de asistencia humanitaria, además de nuevas formas de financiación como la acordada en la Cumbre Humanitaria Mundial a través del "gran pacto», es importante mejorar la coordinación entre las agencias internacionales humanitarias, que reciben buena parte de los recursos, con los agentes locales, impulsando la capacidad local a través de estrategias a largo plazo y no mediante planes anuales como es habitual. Debido al cambio constante de las necesidades de la población en los conflictos armados prolongados, una mayor sinergia entre los diferentes actores humanitarios internacionales y locales en un plano de igualdad contribuye a una mayor eficacia de la acción humanitaria en este tipo de escenarios.

106 Commitments to Action, op. cit., nota 103, p. 25. 
La Cumbre Humanitaria Mundial constituye un punto de inflexión al reconocer la importancia del empoderamiento de las ONG locales y nacionales y por tanto, pasar de una ayuda humanitaria "top-down» a una de tipo «bottom-up». Las ONG del Sur y los «nuevos» donantes reclaman un mayor reconocimiento de su labor y promueven otras formas de ayuda humanitaria. Sin embargo, la localización de la ayuda humanitaria también puede tener una doble lectura, más de carácter neoliberal, y es que sobre la base de las estrategias de resiliencia de la población afectada, se haga un uso interesado del empoderamiento local al considerar que la población se puede «salvar por sus propios medios», liberando así de responsabilidad a las agencias internacionales humanitarias y dejando toda la responsabilidad en las ONG nacionales y locales.

\section{RESUMEN}

\section{RETOS DE LA AYUDA HUMANITARIA EN CONFLICTOS ARMADOS PROLONGADOS: EL ROL CRECIENTE DE LOS AGENTES LOCALES}

Los conflictos prolongados como los de Yemen y Siria, la obstaculización constante de la ayuda humanitaria, la hambruna como arma de guerra, el aumento de la violencia contra las operaciones humanitarias y el difícil acceso por parte de las agencias internacionales a la población necesitada es una constante. Otorgar un mayor protagonismo a los agentes locales e «invertir en la humanidad» es una responsabilidad básica compartida según el Secretario General de las Naciones Unidas. No obstante, en el 2014, los agentes locales tan solo recibieron directamente el 0,2 por 100 de la financiación humanitaria internacional. Los retos de la ayuda humanitaria pasan, entre otros, por la necesidad de un mayor entendimiento entre agentes locales y agentes internacionales de la dinámica de poder en entornos de conflicto y una mayor integración de la ayuda humanitaria en iniciativas más amplias dirigidas a la transformación de las causas estructurales del conflicto. La Primera Cumbre Humanitaria Mundial celebrada en Estambul en mayo de 2016 ha puesto el foco en el empoderamiento de las ONG locales y nacionales como una nueva forma de trabajar y hacer más eficaz la ayuda humanitaria.

Palabras clave: ayuda humanitaria, conflictos armados prolongados, agentes humanitarios locales, hambruna como arma de guerra, denegación arbitraria de la ayuda humanitaria.

\section{ABSTRACT \\ CHALLENGES OF HUMANITARIAN AID IN PROTRACTED ARMED CONFLICT: THE INCREASING ROLE OF LOCAL AGENTS}

Protracted armed conflicts such as Yemen and Syria, the hindering humanitarian aid, the use of starvation as a weapon of war, the increasing violence against humanitarian operations and the difficult access by international agencies to the people in need has become a commonplace. To give greater prominence to local actors and to «invest in people» is a basic shared responsibility according to the Secretary General of the United Nations. However, in 2014 , local agents only received directly 0.2 per cent of international humanitarian funding. The challenges of humanitarian aid are, among others, the need for greater understanding between local and international agents of the power dynamics during con- 
flicts and a greater integration of humanitarian aid into broader initiatives aimed at transforming the structural roots of conflicts. The First World Humanitarian Summit held in Istanbul in May 2016 has put the focus on empowering local and national NGOs as a new way of working and make humanitarian aid more effective.

Keywords: humanitarian aid, protracted armed conflict, local humanitarian agents, starvation as a weapon of war, arbitrary denial of humanitarian access. 